\section{Location and Temperature Effects on Soft Scald in 'Honeycrisp' Apples}

\author{
Cindy B.S. Tong, David S. Bedford, James J. Luby, and \\ Faye M. Propsom \\ Department of Horticultural Science, University of Minnesota, 1970 Folwell \\ Avenue, St. Paul, MN 55108 \\ Randolph M. Beaudry \\ Department of Horticulture, Michigan State University, A22 Plant and Soil \\ Science Building, East Lansing, MI 48824
}

James P. Mattheis

USDA-ARS Tree Fruit Research Laboratory, 1104 N. Western Avenue, Wenatchee, WA 98801

\author{
Christopher B. Watkins \\ Department of Horticulture, Cornell University, Ithaca, NY 14853
}

\section{Sarah A. Weis \\ Department of Plant and Soil Science, University of Massachusetts, Bowditch Hall, Box 30910, Amherst, MA}

Additional index words. Malus $\times$ domestica, mineral composition, fruit maturity

\begin{abstract}
The effects of growing and storage locations and storage temperature on soft scald incidence of 'Honeycrisp' apples were examined. In 1999 and 2000, fruits were produced at five different locations, harvested at two different times, and stored at two or five different storage locations. In 1999, fruits were stored at 0 or $2^{\circ} \mathrm{C}$. Soft scald was only observed in fruits from one growing location and primarily at $0^{\circ} \mathrm{C}$. More soft scald was observed from the second harvest than from the first. Scalded fruits were preclimacteric as determined by ethylene production rate, whereas fruits from the other locations were postclimacteric. In 2000, fruits from four of the growing locations developed soft scald, and soft scald incidence was not related to ethylene production rate. Scalded fruits had higher concentrations of phosphorus, boron, and magnesium, and lower concentrations of manganese than unaffected fruit. Development of soft scald was not related to fruit ethylene production rates, was dependent on growing location, increased with later harvest, and may be related to fruit elemental content.
\end{abstract}

'Honeycrisp' is a relatively new apple cultivar that has been released by the Minnesota Agricultural Experiment Station (Luby and Bedford, 1992). 'Honeycrisp' fruit remain crisp for up to 6 months in cold storage, and consumers like the fruit texture and flavor (Tong et al., 1999). Positive grower and consumer acceptance has led to extensive plantings in the United States, with $\approx 950,000$ trees planted as of Jan. 2001 (unpublished data). Of concern to the North American apple industry, however, have been reports of the erratic occurrence within 3 months of storage of the physiological disorder, soft scald.

Soft scald is a low temperature storage disorder that results in browning of the skin

Received for publication 10 Apr. 2002. Accepted for publication 4 Nov. 2002. Partial financial support for this study was provided by the Minnesota Agricultural Experiment Station and USDAregional project NE-103. We thank Frank Martin for statistical advice, Jennifer Alton and Roger Meissner for harvest assistance, Michael Fargione and Kevin Iungerman for assistance in identifying study sites in New York, and Jacqueline Nock for technica assistance. Mention of a trademark name or proprietary product does not constitute a guarantee by the Univ. of Minnesota.

HortScience, Vol. 38(6), OCTOBER 2003 in the cultivar. The disorder was not observed during selection of the cultivar in Minnesota; thus, an interesting question arose as to how incidence of the disorder could be affected by growing region and harvest date. Five locations in the United States were selected to test the hypothesis that soft scald susceptibility was related to climatic conditions.

\section{Materials and Methods}

Plant material. This study was performed using fruits harvested in 1999 and 2000. In 1999, 'Honeycrisp' fruits were obtained from commercial orchards in New York (lat. $41^{\circ} 45^{\prime}$ $\mathrm{N}$ ), Washington (lat. $46^{\circ} 12^{\prime} \mathrm{N}$ ), and university orchards in Massachusetts (lat. $42^{\circ} 44^{\prime} \mathrm{N}$ ), Michigan (lat. $42^{\circ} 44^{\prime} \mathrm{N}$ ), and Minnesota (lat. $45^{\circ} 52^{\prime} \mathrm{N}$ ). There were two harvests per location, with the first harvest occurring at the commercially "acceptable" time for each region. Indices of commercial acceptability are still being developed because this cultivar is relatively new. Therefore, harvest maturity of the fruit differed from location to location, and was determined by ethylene production rates. Ethylene production rates were used instead of starch indices, as ethylene production rates are an objective measure of physiological maturity, and preclimacteric and climacteric 'Honeycrisp' fruits can have similar starch index numbers. The second harvest took place 2 weeks after the first. Due to an extensive preharvest drop of fruit in the New York orchard used in 1999, only one harvest was completed.

In 2000, fruits from Massachusetts and Michigan were picked when green and preclimacteric. Fruits from the other three locations were harvested when climacteric. Fruits from Wash. were obtained from a different orchard (lat. $47^{\circ} 37^{\prime} \mathrm{N}$ ) than that used in 1999 . Fruits in $\mathrm{N}$.Y. were obtained from the Champlain region $\left(44^{\circ} 41^{\prime} \mathrm{N}\right)$ where most New York 'Honeycrisp' plantings are located.

Shipping, storage, and evaluation. In 1999 , half of the fruits from each growing location were shipped via overnight air express to each of the other locations for storage. Unshipped fruits were held at room temperature at each growing location for $24 \mathrm{~h}$ prior to cold storage. This was done so that fruit at originating locations were put into cold storage at approximately the same time as shipped fruits. Fruits were stored for at least 3 months at 0 or $2{ }^{\circ} \mathrm{C}$, temperatures commonly used industrially for apple storage, in cardboard boxes without plastic liners.

In 2000, fruits were stored only in Minnesota, but at two different locations. This was done to decrease the amount of fruits needed for the experiment while allowing for replication of storage location. Two cartons of fruits from each harvest at Massachusetts, Michigan, New York, and Washington were shipped via overnight air express to Minnesota. One carton was stored at the Univ. of Minnesota campus in St. Paul, and the other carton at the Horticulture Research Center in Chanhassen. All fruits were stored for at least 3 months at $0{ }^{\circ} \mathrm{C}$ in cardboard boxes without plastic liners. Fruits from Minnesota were also 
stored at both locations. Each cooler contained only apples.

Ethylene production rates were measured at harvest at each growing location and upon arrival in St. Paul. Only arrival data are reported because ethylene production rates upon arrival were similar to those at harvest. In St. Paul, 10 fruits were randomly chosen from a shipment, and placed into gastight jars, one fruit per jar. Ethylene was measured using a static system as described by Plank and Tong (1997). In 1999, fruits were evaluated once a month for incidence of soft scald. In 2000, fruits were evaluated only after 3 months of storage.

Elemental analyses. Three fruits with soft scald and three unaffected fruits from each of three growing locations and each storage location were collected in 2000 after 3 months of storage, providing three replicates per growing location and storage location. About $200 \mathrm{~g}$ of tissue, including skin and flesh but excluding core tissue, from each fruit was cut off with a knife. In fruits with soft scald, the samples included the band of affected tissue to a depth of $\approx 1-2 \mathrm{~cm}$. In control fruits where there was no soft scald, comparable parts of the apples were sampled. The samples were freeze-dried, then ground with a mortar and pestle. Individual samples were analyzed separately for elemental content $(\mathrm{P}, \mathrm{K}, \mathrm{Ca}, \mathrm{Mg}, \mathrm{Mn}, \mathrm{Al}, \mathrm{Fe}, \mathrm{Na}, \mathrm{Zn}$, $\mathrm{Cu}, \mathrm{B}, \mathrm{Pb}, \mathrm{Ni}, \mathrm{Cr}$, and $\mathrm{Cd}$ ). Concentrations of elements were determined using inductively coupled plasma (ICP) emission spectroscopy (Munter and Grand, 1981). Average concentrations from the three replicates of each growing location and storage location were used for statistical analyses.

Statistical analyses. In 1999, the experimental design was completely randomized. Data were analyzed using the GLM procedure of SAS (SAS Institute, Cary, N.C.). The experimental design for 2000 was an incomplete nested split-plot, with storage locations as main plots and growing locations as subplots. Data were analyzed using the unweighted least squares linear regression procedure of Statistix. Scald was regressed against growing locations, harvest date, and ethylene production. Elemental data were analyzed using the univariate analysis of variance procedure of SPSS. Mean separations were done using least square differences, with $P=0.05$.

\section{Results and Discussion}

1999 study. In 1999, storage location, harvest date, and storage time (duration) had highly significant effects on soft scald incidence (Table 1). Soft scald was mainly observed in fruits originating from Michigan and was greater for fruits from the second harvest than the first. Therefore, for clarity, only data on Michigan-grown apples from the second harvest are shown in Table 1. No soft scald was observed in fruits originating from Massachusetts, New York, or Washington. The major difference between fruits grown in Michigan and elsewhere was that the Michigan-grown fruits were preclimacteric at the first harvest (Table 2), while the other fruits were climacteric. Incidence of soft scald was lessened, but not totally alleviated, with $2{ }^{\circ} \mathrm{C}$ storage.

Seventeen percent soft scald was observed for Michigan-grown fruits from the first harvest stored in Washington. Also, soft scald was observed in Minnesota-grown fruits from the second harvest, but only when stored in Minnesota, at levels of $3 \%, 5 \%$, and $5 \%$ at 1,2 , and 3 months at $0{ }^{\circ} \mathrm{C}$, respectively. This may have occurred because, unlike fruits from other growing locations, the Minnesota-grown fruits were placed directly into cold storage in Minnesota following harvest, which did not mimic temperatures, presumably warmer than $0{ }^{\circ} \mathrm{C}$, during transit to the other locations.

Initially, because soft scald had not been observed in Minnesota-grown 'Honeycrisp' fruits, but reported for fruits from other regions of the United States, it was thought that soft scald incidence might be related to climatic conditions, and that Minnesota would have significantly colder mean fruiting season (March-October) temperatures than the other states. However, a comparison of mean fruiting season temperatures as reported by National Weather Service Cooperative Stations near the orchards at different growing locations suggest that mean temperatures, mean minimum temperatures, and mean maximum temperatures are unrelated to soft scald development. For example, the mean monthly temperatures, mean minimum temperatures, and mean maximum temperatures in 1999 for the fruiting season (March-30 Sept.) near the Massachusetts and Michigan orchards were the same: 15.4, 8.6 , and $22.3{ }^{\circ} \mathrm{C}$, respectively. However, the Michigan fruit developed soft scald and the Massachusetts fruit did not. Also, Minnesota mean monthly temperatures, mean minimum temperatures, and mean maximum temperatures for the same period were 14.7, 9.4, and $20^{\circ} \mathrm{C}$, respectively, not much lower than those in Massachusetts and Michigan.

2000 study. In 2000, fruits from Massachusetts and Michigan were purposely harvested at the preclimacteric stage to test the hypothesis that immature fruit were more susceptible to soft scald. Soft scald was observed in fruits from Michigan, New York, and Washington (Table 3). No or little soft scald was observed in fruits from Massachusetts and Minnesota, except for fruits from the first harvest in Minnesota stored in Chanhassen.

Fruit maturity alone does not seem to explain soft scald incidence because fruits from both Massachusetts and Michigan were harvested when preclimacteric. Linear regression analyses showed that harvest date, but not fruit maturity as determined by ethylene production rate, had a significant effect on soft scald incidence (Table 3 ). The effect of harvest date was evident in increased soft scald incidence in fruits from the second harvest compared to those from the first harvest for most growing locations.

Surprisingly, in 1999 soft scald was not observed in Michigan-grown fruits stored in Michigan. It was thought that because the Michigan-grown fruits were preclimacteric, they were more susceptible to soft scald. However, the 2000 data showed that this is not true, as preclimacteric Massachusetts-
Table 1. Percentage of soft scald incidence accumulated per month reported by each storage location for Michigan-grown apples from the second harvest in 1999 and analysis of variance. Soft scald was not observed in fruit grown in other locations except Minnesota (see text). Mean squares are from type III (partial) sum of squares.

\begin{tabular}{lccc}
\hline \multirow{2}{*}{ Storage location } & Months & \multicolumn{2}{c}{$\%$ Soft scald } \\
\cline { 3 - 4 } Massachusetts & 1 & 12 & 6 \\
& 2 & 31 & 13 \\
\multirow{3}{*}{ Michigan } & 3 & 31 & 13 \\
& 1 & 0 & 0 \\
Minnesota & 2 & 0 & 0 \\
& 3 & 0 & 0 \\
\multirow{2}{*}{ New York } & 1 & 0 & 0 \\
& 2 & 17 & 1 \\
Washington & 3 & 19 & 1 \\
& 1 & 0 & 0 \\
& 2 & 13 & 3 \\
& 3 & 15 & 3 \\
& 3 & 25 & 0
\end{tabular}

Factor $^{2} \quad$ df Mean squares

\begin{tabular}{lll}
\hline Storage location & 4 & $0.0125^{*}$ \\
Harvest & 1 & $0.0022^{* *}$ \\
Storage temp & 1 & 0.2486 \\
Storage time & 3 & $0.0205^{*}$ \\
Stloc $\times$ harv & 4 & 0.2641 \\
Stloc $\times$ temp & 4 & 0.6992 \\
Stloc $\times$ time & 5 & $0.0251^{*}$ \\
Harv $\times$ temp & 1 & $0.0077^{* *}$ \\
Harv $\times$ time & 3 & $0.0182^{*}$ \\
Temp $\times$ time & 3 & 0.1236 \\
Stloc $\times$ harv $\times$ temp & 4 & $0.0147^{*}$ \\
Stloc $\times$ harv $\times$ time & 5 & $0.0360^{*}$ \\
Harv $\times$ temp $\times$ time & 3 & 0.1109 \\
\hline Stloc
\end{tabular}

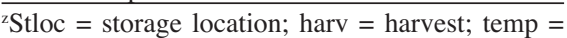
storage temperature; and time $=$ storage time.

${ }^{* *}$, *Significant at $P=0.01$ or 0.05 , respectively.

Table 2. Ethylene production rates of 1999 fruit from all growing locations upon receipt in St. Paul, Minn., and analysis of variance. There was only one harvest from New York. Mean squares are from type III (partial) sum of squares.

\begin{tabular}{lcc}
\hline & \multicolumn{2}{c}{$\mathrm{C}_{2} \mathrm{H}_{4}\left(\mu \mathrm{L} \cdot \mathrm{kg}^{-1} \cdot \mathrm{h}^{-1}\right)$} \\
\cline { 2 - 3 } Growing location & Harvest 1 & Harvest 2 \\
\hline Massachusetts & 5.2 & 17.8 \\
Michigan & 0.5 & 3.9 \\
Minnesota & 19.6 & 7.8 \\
New York & 18.6 & --- \\
Washington & 42.6 & 5.0 \\
Factor & df & Mean squares \\
\hline Location & 4 & 1152 \\
Harvest & 1 & 1350 \\
Location $\times$ harvest & 3 & $2301^{*}$ \\
\hline
\end{tabular}

*Significant at $P=0.05$.

grown fruits did not develop soft scald. We do not have an explanation for why soft scald was not observed in Michigan-grown fruits stored in Michigan but observed at the other storage locations in 1999. Although shipping conditions and slight variations among storage conditions at the different locations may explain differences in percentages of soft scald incidence observed, they cannot explain why no soft scald was observed in Michigan-grown fruits stored in Michigan in 1999.

Elemental analyses. In 1999, we observed that fruits developing soft scald did not usually develop bitter pit, a physiological disorder linked to calcium deficiency. Therefore, we 
Table 3. Percentage of soft scald incidence observed after 3 months of storage of fruit harvested in 2000 and regression analysis where constant $=$ Minnesota; and independent variables 1, 2, 3, and $4=$ Washington, Massachusetts, Michigan, and New York, respectively. Ethylene was not a significant factor.

\begin{tabular}{|c|c|c|c|}
\hline \multirow{2}{*}{$\begin{array}{l}\text { Storage } \\
\text { location }\end{array}$} & \multirow{2}{*}{$\begin{array}{l}\text { Growing } \\
\text { location }\end{array}$} & \multicolumn{2}{|c|}{$\%$ Soft scald } \\
\hline & & Harvest 1 & Harvest 2 \\
\hline \multirow[t]{5}{*}{ Chanhassen } & Massachusetts & 0 & 0 \\
\hline & Michigan & 20 & 30 \\
\hline & Minnesota & 31 & 2 \\
\hline & New York & 12 & 74 \\
\hline & Washington & 4 & 40 \\
\hline \multirow[t]{5}{*}{ St. Paul } & Massachusetts & 0 & 0 \\
\hline & Michigan & 12 & 18 \\
\hline & Minnesota & 2 & 0 \\
\hline & New York & 11 & 65 \\
\hline & Washington & 8 & 40 \\
\hline \multicolumn{2}{|l|}{ Variables } & \multicolumn{2}{|c|}{ Coefficient } \\
\hline \multicolumn{2}{|l|}{ Constant } & \multicolumn{2}{|c|}{-16.6} \\
\hline \multicolumn{2}{|c|}{ Independent variable 1} & \multicolumn{2}{|c|}{14.25} \\
\hline \multicolumn{2}{|c|}{ Independent variable 2} & \multicolumn{2}{|c|}{-8.75} \\
\hline \multicolumn{2}{|c|}{ Independent variable 3} & \multicolumn{2}{|c|}{11.25} \\
\hline \multicolumn{2}{|c|}{ Independent variable 4} & \multicolumn{2}{|c|}{$31.75^{*}$} \\
\hline \multicolumn{2}{|c|}{ Harvest date } & \multicolumn{2}{|c|}{$16.9^{*}$} \\
\hline
\end{tabular}

*Significant at $P=0.05$.

Table 4. Elemental concentrations of fruit with soft scald compared to unaffected fruit, and for all fruit (scalded and unaffected) from the three different growing locations, and stored in Chanhassen or St. Paul. Nonsignificant interactions are not shown in the analysis of variance. Mean squares are from type III (partial) sum of squares.

\begin{tabular}{|c|c|c|c|c|c|}
\hline & & Phosphorus & Boron & Magnesium & Manganese \\
\hline & & \multicolumn{4}{|c|}{ 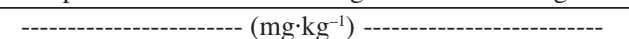 } \\
\hline Unaffected & & 551 & 11.7 & 305 & 4.4 \\
\hline Soft scald & & 618 & 14.6 & 360 & 2.9 \\
\hline Michigan & & 620 & 7.3 & 328 & 6.2 \\
\hline Minnesota & & 521 & 19.2 & 257 & 2.0 \\
\hline Washington & & 611 & 13.0 & 413 & 2.8 \\
\hline Source & $\mathrm{df}$ & \multicolumn{4}{|c|}{ Mean squares } \\
\hline Storage location & 1 & 3366 & 1.9 & 749 & 0.200 \\
\hline Growing location & 2 & $11897^{* *}$ & $141^{* *}$ & $24408^{* *}$ & $20^{* *}$ \\
\hline Scald & 1 & $13461^{*}$ & $26^{* *}$ & $9094^{* *}$ & $7^{*}$ \\
\hline Grloc $\times$ scald $^{2}$ & 2 & 2234 & 3 & 127 & $6^{*}$ \\
\hline
\end{tabular}

${ }^{\mathrm{z}} \mathrm{Grloc}=$ growing location .

${ }^{* *}$, *Significant at $P=0.01$ or 0.05 , respectively.

decided to measure levels of elements in soft scalded fruits. Of all the elements measured by ICP, significant differences were observed in concentrations of phosphorus, boron, magnesium, and manganese between unaffected fruit tissue and those with soft scald (Table 4). Scalded fruit tissue had higher concentrations of phosphorus, boron, and magnesium, and lower concentrations of manganese than unaffected tissue. Unlike superficial scald (Johnson, 2000), there was no difference in calcium content. There were also significant effects due to growing location, but not due to storage location.

Our study verifies anecdoctal reports that
'Honeycrisp' fruits can develop soft scald in storage. Our data suggest that soft scald incidence is orchard-specific. More soft scald was observed both years in fruits from the later harvest compared to the first. However, fruit maturity, as measured by ethylene production rate, did not have a significant effect on soft scald incidence. Fruits from the second harvest were only 2 weeks older than those from the first harvest, suggesting that changes occurring in the fruits while still on the tree must lead to soft scald susceptibility. There are no previous reports on elemental content related to soft scald. It is not known whether the differences in elemental content between unaffected and scalded fruits occur prior to or during storage because elemental content was measured in fruits at the end of storage and not at harvest.

Perhaps other factors, such as cropping load and soil fertility, affect soft scald susceptibility. Rootstock is another factor that may play a role, however, not by itself. The 1999 New York apples were obtained from trees on M.26 rootstock and did not develop soft scald, while the 2000 New York apples, also from trees on M.26 rootstock, did. No one factor alone, but rather a combination of factors may determine soft scald susceptibility. Future research is needed to determine whether there is a nutritional component to soft scald susceptibility, and if other factors interact to produce soft scald.

\section{Literature Cited}

Emonger, V.E., D.P. Murr, and E.C. Lougheed. 1994. Preharvest factors that predispose apples to superficial scald. Postharv. Biol. Tech. 4: 289-300.

Fan, X., J.P. Mattheis, and S. Blankenship. 1999. Development of apple superficial scald, soft scald, core flush, and greasiness is reduced by MCP. J. Agr. Food Chem. 47:3063-3068.

Gerhardt, F. and G.F. Sainsbury. 1952. Soft scald and its control in Delicious apples. Proc. Wash. State Hort. Assoc. 48:97-100.

Hopkirk, G. and R.G.H. Wills. 1981. Variation in fatty acid composition of apples in relation to soft scald. Phytochemistry 20:193-195.

Johnson, D.S. 2000. Mineral composition, harvest maturity and storage quality of 'Red Pippin', 'Gala' and 'Jonagold' apples. J. Hort. Sci. Biotechnol. 75:697-704.

Luby, J.J. and D.S. Bedford. 1992. Honeycrisp apple. Univ. Minn. Agr. Expt. Sta. Rpt. 225-1992 (ADMR-5877-B).

Munter, R.C. and R.A. Grand. 1981. Plant tissue and soil extract analyses by ICP-atomic absorption emission spectrometry, p. 653-672. In: R.M. Barnes (ed.). Developments in atomic plasma dpectrochemical analysis. Heyden, London.

Plank, D.W. and C.B. Tong. 1997. Chelator used in pectin extraction triggers ethylene production by tomato fruit. Physiol. Plant. 99:119-128.

Snowdon, A.L. 1990. A color atlas of post-harvest diseases and disorders of fruits and vegetables, vol. 1. CRC Press, Boca Raton, Fla.

Tong, C., D. Krueger,Z. Vickers, D. Bedford, J.Luby, A. El-Shiekh, K. Shackel, and H. Ahmadi. 1999. Comparison of softening-related changes during storage of 'Honeycrisp' apples, its parents, and 'Delicious'. J. Amer. Soc. Hort. Sci. 124: 407-415.

Wills, R.B.H. 1973. Relationship between hexanol levels in apples and the development of soft scald. J. Hort. Sci. 48:165-168.

Wills, R.B.H., K.J. Scott, and G. Hopkirk. 1977. Reduction of soft scald in apples with methyl linoleate. HortScience 12:72-73. 